\title{
Sequential Extraction of Some Heavy Metals in Southwest Giza Soil, Egypt
}

\author{
S. A. Salman ${ }^{\text {1* }}$ E. M. Abu El Ella ${ }^{2}$, A. A. Elnazer ${ }^{1}$ \\ ${ }^{1}$ Geological Sciences Department, National Research Centre, 33 El Bohouth Street \\ (Formerly El Tahrir Street), P.O. Box 12622, Dokki, Giza, Egypt \\ ${ }^{2}$ Geology Department, Faculty of Science, Assiut University, Assiut-71516, Egypt
}

$\mathbf{T}$ HE POLLUTION of agriculture soil in southwest Giza, Egypt with As, Cd, Pb and $\mathrm{Cr}$ were assessed by the application of Index of Geoaccumulation $\left(\mathrm{I}_{\text {geo }}\right)$ and five steps sequential extractions technique. The results indicated that the soils are muddy sand, alkaline $(\mathrm{pH} \approx 8.3)$, calcareous $\left(\mathrm{CaCO}_{3}>5 \%\right)$ and have low organic matter (3.1\%). Soil contains about $142.8,1.7,123.5$ and $209.1 \mathrm{ppm}$ of $\mathrm{As}, \mathrm{Cd}, \mathrm{Pb}$ and $\mathrm{Cr}$, respectively. The $\mathrm{I}_{\text {geo }}$ indicated that the soils of the study area ranged from uncontaminated-moderately to extremely contaminated. The sequential extraction showed the incorporation of $\mathrm{Pb}$ and $\mathrm{Cr}$ in the residual fraction and the incorporation of $\mathrm{As}$ and $\mathrm{Cd}$ in the carbonate fraction. The exchangeable fraction contains 9, 7.9, 5.1 and $2.6 \%$ of $\mathrm{As}, \mathrm{Cd}, \mathrm{Pb}$ and $\mathrm{Cr}$ extracts, respectively. The environmental risk in the study area comes from the presence of $10.4 \mathrm{ppm}$ As in the exchangeable fraction. The risk assessment code illustrated that $\mathrm{Pb}$ ranged from low to medium risk, $\mathrm{Cr}$ medium to high risk, As high to very high risk and $\mathrm{Cd}$ shows very high risk. These results reflect the mixed sources (geogenic and anthropogenic) of metals in the soil of the study area.

Keywords: Bioavailable, Giza, Egypt, Heavy metals, Anthropogenic, Sequential extraction, Soil pollution.

\section{Introduction}

The industrial, agriculture and transportation activities have an adverse effect on the water and soil quality. These activities release a high amount of chemical pollutants (especially heavy metals) into the environment. The accumulation of heavy metals in soil and water above their normal ranges adversely affect the health of biota. The toxicity, persistent and non-biodegradable characteristics of heavy metals make them one of the most serious and widespread environmental pollutants [1].

The total concentration of metals can't be used to predict the bioavailability, toxicity and distribution of them in the environment $[2,3]$. The heterogeneous composition of soil (minerals, salts, hydroxides, humus, liquids and gasses, etc.) not only determines its physical and chemical properties but also the binding mechanism of heavy metals and their occurrence forms in soil [4]. Therefore, the mobility and toxicity of metal are strongly dependent on its chemical form in soil
[5]. Metal availability to plants can be assessed by using selective extraction and chemical speciation. One of the first sequential extraction schemes is that proposed by Tessier et al. [6]. This scheme and its modifications [7-11], have been widely applied to distinguish between exchangeable, metal bound to carbonates, ironmanganese oxides or organic matter and residual metals in soils. In all of the sequential extraction schemes, the exchangeable fraction represents bioavailable part of metal to plants [12]. Watersoluble and exchangeable fractions are considered to be bioavailable; oxide-, carbonate-, and organic-matter-bound fractions may be potentially bioavailable, but the residual fraction is mainly not available to plants and microorganisms.

The study area represents a part of Giza Governorate and lies between longitudes $31^{\circ} 13^{\prime}$ $08^{\prime \prime}$ and $31^{\circ} 19^{\prime} 53^{\prime \prime}$ and latitudes $29^{\circ} 46^{\prime} 40^{\prime \prime}$ ' and $29^{\circ} 54^{\prime} 00^{\prime \prime}$ (Figure 1). This area is characterized by sedimentary rocks ranging in age from Eocene to Recent and arid climate. It is characterized

*Corresponding author: Salman A. Salman (sal_man19@yahoo.com)

Tel.: 01116523923

DOI: 10.21608/EJCHEM.2018.3180.1271

(C)2017 National Information and Documentation Center (NIDOC) 
by complex human activities including big industries (Sugar industries, bricks factories, chemical industries and agricultural chemicals), several petrol stations, crowded traffic, touristic places, agriculture and urbanization. Such human activities had led to the pollution of water resources and soil with heavy metals at El-Minia, Egypt [13]. The sugar and chemical industries at Giza are one of the heaviest metals pollution sources of the Nile [14]. At the study area, Abu El Ella et al. [15] pointed out the role of human activity in the pollution of water resources with heavy metals. Unfortunately, the studied area has not received attention and lacks studies of soil pollution with heavy metals. Therefore, the current research aims to assess the soil pollution with $\mathrm{As}, \mathrm{Cd}, \mathrm{Pb}$ and $\mathrm{Cr}$ and to determine the degree of pollution with these metals through the application of sequential extraction protocol.

\section{Material and Methods}

Surface agricultural soil (15 cm depth) samples from 11 sampling sites were collected (Figure 1). After being air-dried, they were sieved through a $2 \mathrm{~mm}$ sieve. Soil $\mathrm{pH}$ was measured in 1:1 soils to water ratio by using HANNA (HI93300) combined electrode. Calcium carbonate percentage $\left(\mathrm{CaCO}_{3} \%\right)$ was estimated by the titrimetric method. Soil organic matter percentage (SOM \%) was determined according to the modified Walkley and Black method [16]. The soil samples were dried at $110{ }^{\circ} \mathrm{C}$ for $3 \mathrm{hrs}$, then ground to pass through a 63 -mesh sieve, and homogenized for analysis. For the determination of total metal concentration, exactly $1 \mathrm{~g}$ of powdered soil sample was digested with aqua regia $\left(1 \mathrm{HNO}_{3}: 3 \mathrm{HCl}\right)$. The concentrations of As, $\mathrm{Cd}, \mathrm{Pb}$, and $\mathrm{Cr}$ were determined using atomic absorption spectroscopy (model AA 650).

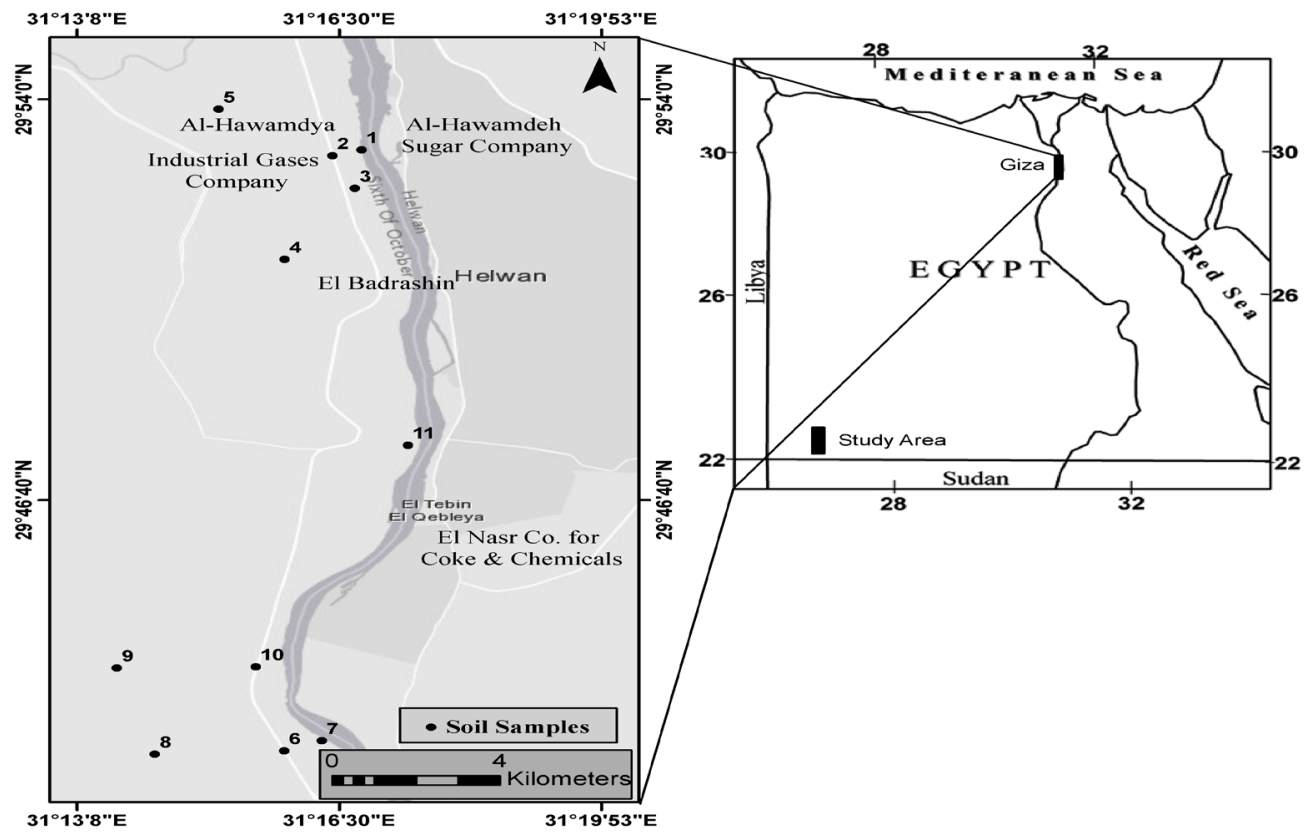

Fig.1. Location map of the study area and sampling sites.

Index of geoaccumulation $\left(\mathrm{I}_{\mathrm{geo}}\right)$ [17], was applied to assess the degree of soil pollution with heavy metals in this study. This method is used because it is a useful tool for the prediction of soil pollution and had been used by many authors as Sarkar et al. [1], Zheng et al. [18] and Milicevic et al. [19].

$$
I_{\text {geo }}=\log _{2}\left(C_{m} / 1.5 * B_{m}\right)
$$

Where $\mathrm{C}_{\mathrm{m}}$ is the measured concentration of the examined metal $(\mathrm{m})$ in the soil samples and $\mathrm{B}_{\mathrm{m}}$ is the geochemical background value of the same metal (m). The constant 1.5 is used for the possible variations of the background data due to the lithogenic effects. The background reference in this study is based on the world soil average abundance of metals $(\mathrm{Pb}=25, \mathrm{Cd}=0.5$ and $\mathrm{Cr}=$ $54 \mathrm{ppm}$ ) [4] and $\mathrm{As}=5$ [20]. The following seven grades of the $\mathrm{I}_{\text {geo }}$ are distinguished [17]:-

Egypt.J.Chem. 61, No.5 (2018) 


\begin{tabular}{cll}
\hline Grade & Value & Soil quality \\
\hline $\mathbf{1}$ & $\mathrm{I}_{\text {geo }} \leq 0$ & uncontaminated \\
$\mathbf{2}$ & $0<\mathrm{I}_{\text {geo }}<1$ & uncontaminated to moderately contaminated \\
$\mathbf{3}$ & $1<\mathrm{I}_{\text {geo }}<2$ & moderately contaminated \\
$\mathbf{4}$ & $2<\mathrm{I}_{\text {geo }}<3$ & moderately to strongly contaminated \\
$\mathbf{5}$ & $3<\mathrm{I}_{\text {geo }}<4$ & strongly contaminated \\
$\mathbf{6}$ & $4<\mathrm{I}_{\text {geo }}<5$ & strongly to extremely contaminated \\
$\mathbf{7}$ & $\mathrm{I}_{\text {geo }}>5$ & extremely contaminated \\
\hline
\end{tabular}

In this study, we used the modified scheme of Tessier et al. [6] adapted from Gleyzes et al. [21] and Phuong [11], as the following:-

1. Exchangeable fraction (F1): $1 \mathrm{~g}$ of soil was attacked by $25 \mathrm{~mL}$ of $1 \mathrm{M} \mathrm{CH}_{3} \mathrm{COONH}_{4}$ at $\mathrm{pH}$ of 7 in $50 \mathrm{~mL}$ centrifugation tubes for $1 \mathrm{~h}$ at room temperature with continuous shaking. Sample collecting: then the mixture was centrifuged for $20 \mathrm{~min}$ at $4500 \mathrm{rpm}$. The supernatant was decanted and filtered through $0.45 \mu \mathrm{m}$ membrane filters. The solid residue was rinsed with $10 \mathrm{~mL}$ deionized water, centrifuged and then discards the rinse before the next extraction reagent is added.

2. Carbonate fraction (F2): The residue from (1) was extracted with $25 \mathrm{~mL}$ of $1 \mathrm{M} \mathrm{CH}_{3} \mathrm{COONa}$ adjusted to $\mathrm{pH} 5$ with $\mathrm{CH}_{3} \mathrm{COOH}$. The experiment was allowed to continue for $4 \mathrm{~h}$ at room temperature. Sample collecting: same as the fraction (1).

3. Fraction bound to amorphous and poorly crystalline $\mathrm{Fe}$ and $\mathrm{Mn}$ hydroxides (F3): The residue from (3) was extracted with $25 \mathrm{~mL}$ of $0.04 \mathrm{M}$ hydroxylamine hydrochloride $\left(\mathrm{NH}_{2} \mathrm{OH} . \mathrm{HCl}\right)$ in $25 \% \mathrm{v} / \mathrm{v}$ acetic acid at $\mathrm{pH}$ 3 . The experiment was allowed to shake for $6 \mathrm{~h}$ at $80^{\circ} \mathrm{C}$. Sample collecting: same as the fraction (1).

4. Organic matter and sulfide fraction (F4): For the residue from (2), $25 \mathrm{~mL}$ of $30 \% \mathrm{H}_{2} \mathrm{O}_{2}$ adjusted to $\mathrm{pH} 2$ with $\mathrm{HNO}_{3}$ was added. The mixture was extracted at $35^{\circ} \mathrm{C}$ for $3 \mathrm{~h}$. Sample collecting: same as the fraction (1).

5. Residual fraction (F5): The residue from (4) was decomposed with a mixture of strong acid $3 \mathrm{ml}$ of $\mathrm{HCl}, 5 \mathrm{~mL}$ of concentrated $\mathrm{HNO}_{3}$ and $25 \mathrm{~mL}$ of concentrated HF. The solution was heated about $150-180^{\circ} \mathrm{C}$ on a hot plate for 2 days. Then evaporate the solution at about $250^{\circ} \mathrm{C}$ until nearly dry. Finally, the residue was dissolved in $5 \mathrm{~mL}$ of $6 \mathrm{M} \mathrm{HCl}$ and made up to $50 \mathrm{~mL}$ with distilled water.

All the filtrates collected were acidified with
$\mathrm{HCl}$ prior to elements determination using atomic absorption spectroscopy (model AA 650).

\section{Results and Discussion}

\section{General characteristics}

The measured parameters of the collected soil samples were listed in Table (1). The $\mathrm{pH}$ values varied from 8.1 to 8.5 , indicating the alkalinity of the studied soil. The soil content of $\mathrm{CaCO}_{3}$ is ranged from 7.5 to $12.4 \%$, indicating the calcareous nature of soils. These high $\mathrm{pH}$ values and $\mathrm{CaCO}_{3} \%$ of the studied samples are primarily due to the aridity and the adjacent carbonate rocks. The alkaline $\mathrm{pH}$ will lead to the adsorption of metals on the organic matter particles through the formation of negative charges on the humic substances part of organic matter [22]. This process will assist in the transportation of heavy metals in the environment as indicated by the positive correlation between the studied metals and SOM (Table 2). Calcium carbonate particles often form strong sorption sites for phosphorus and micronutrients rendering them unavailable to plants [23]. Lime acts as a buffer, maintaining soil $\mathrm{pH}$ in the high alkaline range [24]. This appears from the positive correlation $(\mathrm{r}=0.66)$ between $\mathrm{pH}$ and $\mathrm{CaCO}_{3}$ (Table 2). The $\mathrm{pH}$ and $\mathrm{CaCO}_{3}$ are recorded [25] about 7.5 and $7.4 \%$, respectively in the soil of El-Tebbin area on opposite bank of the River Nile. Also, the alkalinity and calcareous nature of soil at El-Saff, southeast Giza, Egypt, were studied [26].

In the studied soils, organic matter (SOM\%) flocculated between 1.34 and 5.21\% (Table 1). Generally, the Egyptian soils contain a low amount of organic matter due to the negligible addition of crop residues and manure, aridity of the area [27] and seasonal tillage operation [28]. These contents are higher than those $(1.95 \%)$ reported by Wahba [26] in the El-Saff soil, Giza, Egypt. The SOM plays important role in adsorption and absorption of metals in soil [29]. SOM represents a promoter of inorganic pollutants interaction with soil. This can be supported by the positive relation between SOM and the studied heavy metals (Table 2). 
TABLE 1. Physical and chemical characteristics of studied agricultural soil samples.

\begin{tabular}{ccccccccccc}
\hline $\mathbf{S .}$ No & $\mathbf{p H}$ & $\mathbf{S O M} \%$ & $\mathbf{C a C O} \%$ & Sand\% & Silt\% & Clay\% & $\begin{array}{r}\text { As } \\
\mathbf{p p m}\end{array}$ & $\begin{array}{r}\mathbf{C d} \\
\mathbf{p p m}\end{array}$ & $\begin{array}{r}\mathbf{C r} \\
\mathbf{p p m}\end{array}$ & $\begin{array}{r}\mathbf{P b} \\
\mathbf{p p m}\end{array}$ \\
\hline $\mathbf{1}$ & 8.4 & 4.37 & 11.6 & 5.1 & 58.5 & 36.5 & 335.4 & 2.1 & 297.6 & 196.1 \\
$\mathbf{2}$ & 8.3 & 3.36 & 10 & 29.1 & 40.5 & 30.4 & 211.4 & 1.95 & 265.6 & 148.8 \\
$\mathbf{3}$ & 8.2 & 1.34 & 7.5 & 82.9 & 5.1 & 12 & 60.8 & 1.45 & 173.7 & 42.1 \\
$\mathbf{4}$ & 8.4 & 5.21 & 12 & 45.6 & 26.6 & 27.8 & 187.7 & 1.55 & 208.1 & 134.2 \\
$\mathbf{5}$ & 8.5 & 3.87 & 12.4 & 43.0 & 34.2 & 22.8 & 211.8 & 1.8 & 245.6 & 146.5 \\
$\mathbf{6}$ & 8.2 & 1.85 & 10.9 & 55.7 & 19.0 & 25.3 & 75.0 & 1.45 & 229.7 & 110.6 \\
$\mathbf{7}$ & 8.2 & 2.79 & 9.9 & 15.2 & 41.8 & 43.0 & 212.6 & 2 & 169.4 & 134.1 \\
$\mathbf{8}$ & 8.4 & 2.35 & 11.1 & 72.2 & 12.7 & 15.2 & 76.4 & 1.35 & 186.7 & 76.2 \\
$\mathbf{9}$ & 8.3 & 2.29 & 9.3 & 74.7 & 11.4 & 13.9 & 77.3 & 1.25 & 141.7 & 81.7 \\
$\mathbf{1 0}$ & 8.1 & 4.61 & 10.4 & 29.1 & 40.5 & 30.4 & 9.2 & 1.6 & 219.5 & 128.0 \\
$\mathbf{1 1}$ & 8.3 & 2.59 & 9.3 & 59.5 & 22.8 & 17.7 & 113.0 & 1.7 & 162.6 & 160.2 \\
Mean & 8.3 & 3.1 & 10.4 & 46.6 & 28.5 & 25.0 & 142.8 & 1.7 & 209.1 & 123.5 \\
\hline
\end{tabular}

S.No.: Sample Number SOM: Soil organic matter

TABLE 2. Correlation coefficient between soil parameters.

\begin{tabular}{lllllllllll}
\hline & $\mathbf{p H}$ & $\mathbf{S O M}$ & $\mathbf{C a C O}_{3}$ & Sand & Silt & Clay & As & $\mathbf{C d}$ & $\mathbf{C r}$ & $\mathbf{P b}$ \\
\hline $\mathbf{p H}$ & 1.00 & & & & & & & & & \\
SOM & 0.40 & 1.00 & & & & & & & & \\
$\mathbf{C a C O}_{3}$ & 0.66 & 0.68 & 1.00 & & & & & & & \\
Sand & -0.16 & -0.65 & -0.46 & 1.00 & & & & & & \\
Silt & 0.25 & 0.69 & 0.50 & -0.98 & 1.00 & & & & & \\
Clay & 0.00 & 0.52 & 0.36 & -0.94 & 0.86 & 1.00 & & & & \\
As & 0.67 & 0.45 & 0.47 & -0.70 & 0.72 & 0.60 & 1.00 & & & \\
Cd & 0.30 & 0.43 & 0.27 & -0.88 & 0.88 & 0.80 & 0.81 & 1.00 & & \\
Cr & 0.40 & 0.53 & 0.59 & -0.65 & 0.71 & 0.50 & 0.61 & 0.61 & 1.00 & \\
Pb & 0.38 & 0.66 & 0.55 & -0.82 & 0.87 & 0.65 & 0.73 & 0.81 & 0.63 & 1.00 \\
\hline
\end{tabular}

The particle size distribution (PSD) is an important issue in environmental research [30]. The obtained results show that the sand fraction is prevailing over the other fractions followed by silt then clay. The studied soils comprise three main groups [31] (Figure 2); mud (No.1), sandy mud (Nos. 2, 3, 5, 8 and 9) and muddy sand (Nos. 4, $6,7,10$ and 11). The muddy nature of the studied soil was assessed by the incorporation of metals in soil because the fine particles are more reactive and have a higher surface area than coarser fractions [32]. This is supported by the positive correlation between silt and clay against studied heavy metals (Table 2). The new inputs of metals into soil adsorbed firstly on the silt particles [32] as appeared from the positive correlation between these metals and silt.
Heavy Metals content

Soil total contents of $\mathrm{As}, \mathrm{Cd}, \mathrm{Cr}$, and $\mathrm{Pb}$ are listed in Table (1). Arsenic content ranged from 9.2 to $335.4 \mathrm{ppm}$. This high concentration of As may be due to the industrial activities, traffic emissions and agricultural practices because the highest concentrations were recorded near the sugar and chemical factories, roadside and residential area. It was reported that industrial activities could increases As in the soil into 20000 ppm [33]. Also, fertilizers are one of the main contributors to As in soil [34]. Soils from other parts of Egypt contain lower concentration of As; soils near Sadat city contain about 10.6 ppm [35], Nile Delta soils contain concentrations from 2.2 to 16 ppm [36] and Kafr El-Sheikh soil contains 
concentrations ranging from 25 to $67.5 \mathrm{ppm}$ [37]. In addition, high range $(152-2130 \mathrm{ppm})$ of As was recorded in the dust near the lead smelter in Egypt [38]. Also, a high concentration of As was recorded in soils near industries worldwide; the industrial Bitterfeld-Wolfen district (in Germany) is contaminated with up to 265 ppm As [39]. Also, As was recorded $29.05-144.3 \mathrm{ppm}$ in the paddy soils southwest China [40], while was 11-1217 ppm in the southern China agricultural soil [41]. The estimated range of $\mathrm{Cd}$ in the studied soils was from 1.25 to $2.1 \mathrm{ppm}$ (Table 1), which is higher than the global average content of $\mathrm{Cd} 0.53$ ppm [4]. On the other hand, other parts of Egypt contain higher concentrations of $\mathrm{Cd}$ such as soils of El-Mehala El-kobra contain 28.9 ppm [42] and soils of Fayoum contain 40.8 ppm Cd [43]. The most important sources of $\mathrm{Cd}$ and $\mathrm{Pb}$ in Egypt are P-fertilizers [44] and atmospheric deposition of traffic exhausts [45].

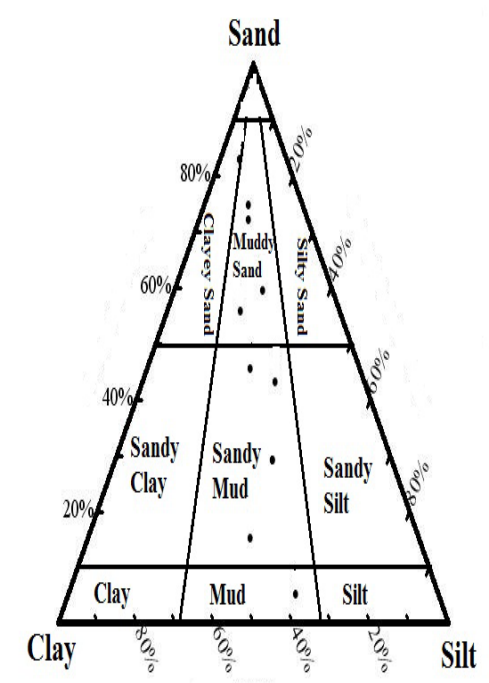

Fig. 2. Folk's [34] diagram of soil classification including the studied soil samples.

The concentration of $\mathrm{Cr}$ in the studied soils varies widely from 141.7 to $297.6 \mathrm{ppm}$ (Table 1). This total $\mathrm{Cr}$ content is significantly higher than the reported worldwide soils Cr (54 ppm) [4]. Such relative higher content of $\mathrm{Cr}$ in the floodplain is attributed to its elevated level in the parent source rocks particularly the ultramafic-mafic rocks of the Ethiopian plateau, where chromium is mainly present substituting iron in the structure of ferromagnesian silicate minerals [46]. This is supported by the positive relation between $\mathrm{Cr}$ and silt in the studied samples (Table 2). Also, the role of the industrial activities appears strongly in the $\mathrm{Cr}$ distribution where the highest concentrations were recorded close to the sugar and chemical factories. The soils of Bahr El-Baker, Egypt contain about 95.01-134.06 ppm of Cr [47]. Also, surface soil of Sohag area contains about $143 \mathrm{ppm}$ of $\mathrm{Cr}$ [48] and soils near Sadat city contains about 129 ppm [36]. The positive correlations (Table 2) between the studied metals indicate that these metals have the same sources and behavior in the study area. The samples closed to the sugar and chemical factories, roadside, bricks factories and residential areas contain the highest levels of the studied metals. The concentrations of $\mathrm{Pb}$ ranged from 42.1 to $196.1 \mathrm{ppm}$ (Table 1), and its mean content (123.5 ppm) is four times greater than the average of worldwide soils (25 ppm) [4]. The $\mathrm{Pb}$ was recorded (314 ppm) in the surface soil of ElSaff, southeast Giza, Egypt [26]. The sources of $\mathrm{Pb}$ in the study area may be the traffic emissions, sugar and chemical industries because the highest concentrations were recorded near the roads and the factories.

Index of geoaccumulation $\left(I_{\text {geo }}\right)$

The calculated $\mathrm{I}_{\text {geo }}$ (Table 3; Figure 3) indicated that the soils of the study area ranged from grade 1 (uncontaminated to moderately contaminated) to grade 7 (extremely contaminated). Arsenic recorded the highest $I_{\text {geo }}$ values; where five samples were strongly contaminated (grade 5), four samples of grade 6 (strongly to extremely contaminated). Only, one sample was of grade 7 (extremely contaminated) and one sample of grade 2 (uncontaminated to moderately contaminated). Cadmium and $\mathrm{Cr}$ were mostly fallen in grade 3 (moderately contaminated). The low variation in the Igeo of these two metals indicated the restriction of their sources in the study area. Six samples were moderately contaminated (grade 3) with $\mathrm{Pb}$, three samples were fallen in grade 4 (moderately to strongly contaminated) and one sample was fallen in grade 2 (uncontaminated to moderately contaminated).

\section{Sequential extraction}

The measured concentrations of $\mathrm{As}, \mathrm{Cd}$, 
TABLE 3. Index of geoaccumulation values for the studied elements.

\begin{tabular}{ccccc}
\hline S. No & As & Cd & Cr & Pb \\
\hline $\mathbf{1}$ & 5.5 & 1.5 & 1.9 & 2.4 \\
$\mathbf{2}$ & 4.8 & 1.4 & 1.7 & 2.0 \\
$\mathbf{3}$ & 3.0 & 1.0 & 1.1 & 0.2 \\
$\mathbf{4}$ & 4.6 & 1.0 & 1.4 & 1.8 \\
$\mathbf{5}$ & 4.8 & 1.3 & 1.6 & 2.0 \\
$\mathbf{6}$ & 3.3 & 1.0 & 1.5 & 1.6 \\
$\mathbf{7}$ & 4.8 & 1.4 & 1.1 & 1.8 \\
$\mathbf{8}$ & 3.3 & 0.8 & 1.2 & 1.0 \\
$\mathbf{9}$ & 3.4 & 0.7 & 0.8 & 1.1 \\
$\mathbf{1 0}$ & 0.3 & 1.1 & 1.4 & 1.8 \\
$\mathbf{1 1}$ & 3.9 & 1.2 & 1.0 & 2.1 \\
\hline
\end{tabular}

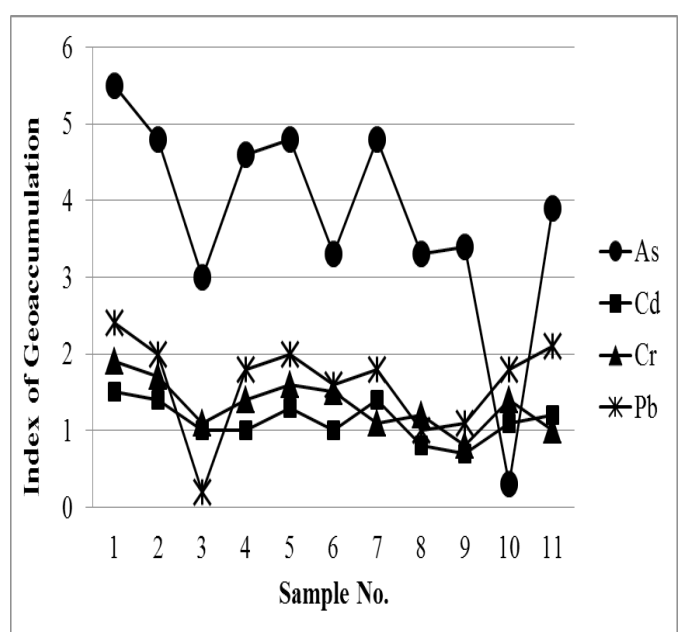

Fig. 3. comparative distribution of Igeo results.

$\mathrm{Pb}$ and $\mathrm{Cr}$ in the conducted five-step sequential extraction were listed in (Table 4) and the percent $(\%)$ of each extract is illustrated in (Figure 4). The Exchangeable $\mathrm{As}, \mathrm{Cd}, \mathrm{Pb}$ and $\mathrm{Cr}$ fraction (F1) concentrations are flocculated around 10.4, $0.1,4.9$ and $4.9 \mathrm{ppm}$, respectively (Table 4). This fraction represents about 9, 7.9, 5.1 and $2.6 \%$ of the total extract, respectively (Fig. 4). These concentrations of the studied metals in the exchangeable fraction are considered the most potentially labile and bioavailable fraction and consequentially the highest toxic to the environment $[49,50]$. This fraction includes the water soluble and exchangeable ions on both of fine particles and organic matter surfaces of soil and accordingly is influenced by clays and organic matter contents of soils [51, 52].
The carbonate fraction contains loosely bound metals (F2). It is important fraction because the studied soils are alkaline, calcareous $(\mathrm{CaCO} 3>5 \%)$ and have low organic matter (Table 1) that lead to the precipitation of metals as carbonates. The carbonate fraction retained about 35.3, 48.5, 6.9 and $26.7 \%$ of the total extract for As, $\mathrm{Cd}$, $\mathrm{Pb}$ and $\mathrm{Cr}$, respectively (Fig. 4). Generally, this fraction is sensitive to $\mathrm{pH}$ changes and the metal can be released from this fraction at $\mathrm{pH}$ close to 5 [20]. The high percentage of As and $\mathrm{Cd}$ in the exchangeable and carbonate fractions indicate the recent anthropogenic input of this element into the soil because these fractions contain the weakly bonded metals [50].

Regarding the third extraction step (F3), hydrous oxides of iron and manganese are extracted together. They are referred to as sink for heavy metals [21, 53].Scavenging by these secondary oxides, present as coatings on mineral surfaces or as fine discrete particles, can occur by any or a combination of the following mechanisms: co-precipitation; adsorption; surface complex formation; ion exchange; and penetration of the lattice $[54,55]$. The recorded average $\mathrm{As}, \mathrm{Cd}, \mathrm{Pb}$ and $\mathrm{Cr}$ concentrations in this fraction were about 21.4, 0.1, 4.4 and 9.8 ppm, respectively (Table 4). In addition, the concentrations of $\mathrm{As}$ and $\mathrm{Cd}$ extracted in this fraction are positively correlated with the total metal concentrations in soil (Figure 5). This positive correlation suggests overloading of the geochemical system by contamination with these metals from anthropogenic sources $[52,56]$.

The organic fraction (F4) content of As, Cd, $\mathrm{Pb}$ and $\mathrm{Cr}$ was flocculated around 19.4, 0.1, 8.6 and $7.3 \mathrm{ppm}$, respectively (Table 4). This fraction represents about $14.9,3.3,4.5$ and $5.3 \%$ of the total $\mathrm{As}, \mathrm{Cd}, \mathrm{Pb}$ and $\mathrm{Cr}$ extract, respectively (Figure 4). Generally, metals bind to SOM through complication and exchangeable processes [57]. The obtained low contents of metals in this fraction may be due to the low SOM\% in the studied soil (Table 1). The organic fraction, nonexchangeable, is not considered very mobile or available since strong metal adsorption by soil organic matter by the formation of metal chelates reduces metal solubility in soil $[55,58]$. 
Finally, in the residual fraction (F5) $\mathrm{Cr}$ and $\mathrm{Pb}$ average concentrations were 117.2 and 89.6 ppm that represent about 61.6 and $74.9 \%$ of total extract, respectively (Figure 4). The high level of these metals in the residual fraction indicates their low mobility [59] and their mixed geogenic and anthropogenic sources. Omer [46] and Abu Khatita [60] pointed out the geogenic source of $\mathrm{Cr}$ and $\mathrm{Pb}$, respectively in the Egyptian soil. The sediments of Lake Nasser, Egypt, which consider the source of the Egyptian soil contain $\mathrm{Pb}$ from 2 to $36.14 \mathrm{ppm}$ [61]. On the other hand, the percent of $\mathrm{As}$ and $\mathrm{Cd}$ in the residual fraction were about 22.6 and $36.7 \%$, respectively indicating the environmental hazard of these metals in the study area. Generally, this fraction indicates the longterm potential risk of heavy metal or toxic metals entering the biosphere [57].

TABLE 4. Sequential extraction results of the studied soil samples (ppm).

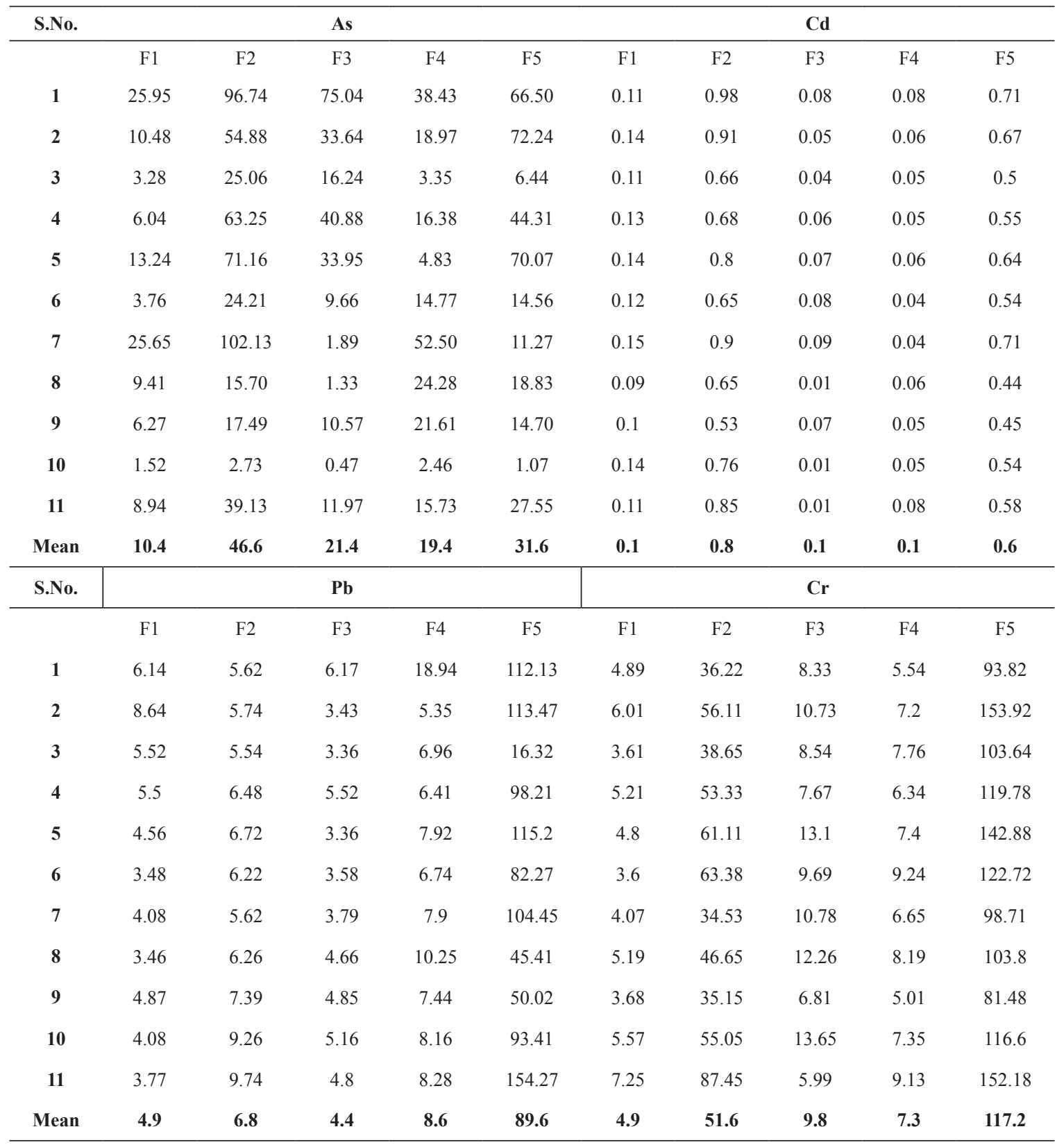

F1: Exchangeable fraction, F2: Carbonate fraction, F3: Fe-Mn fraction, F4: Organic matter fraction and F5: Residual fraction 


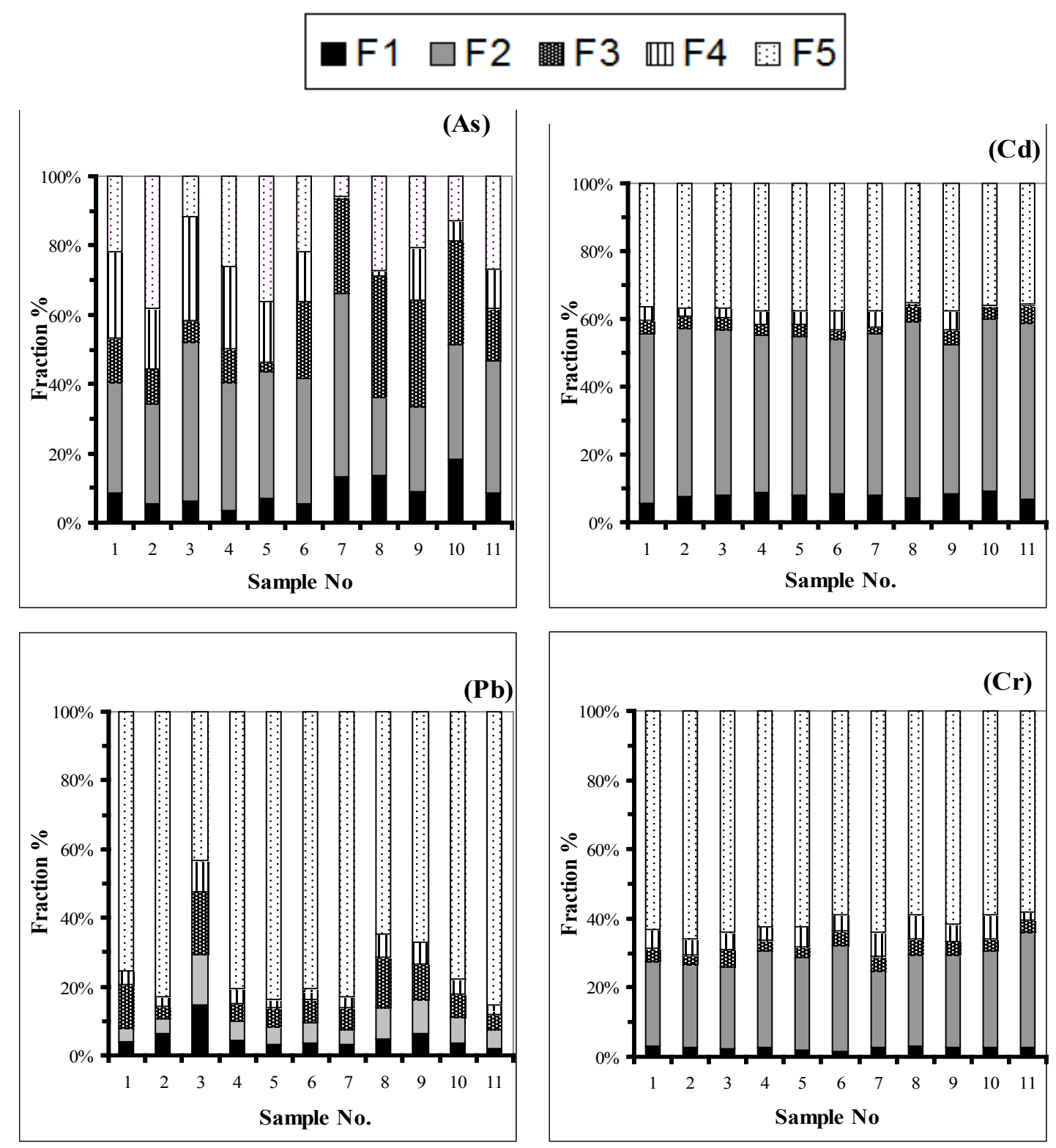

Fig. 4. Sequential extraction percent of metals in the different fractions.
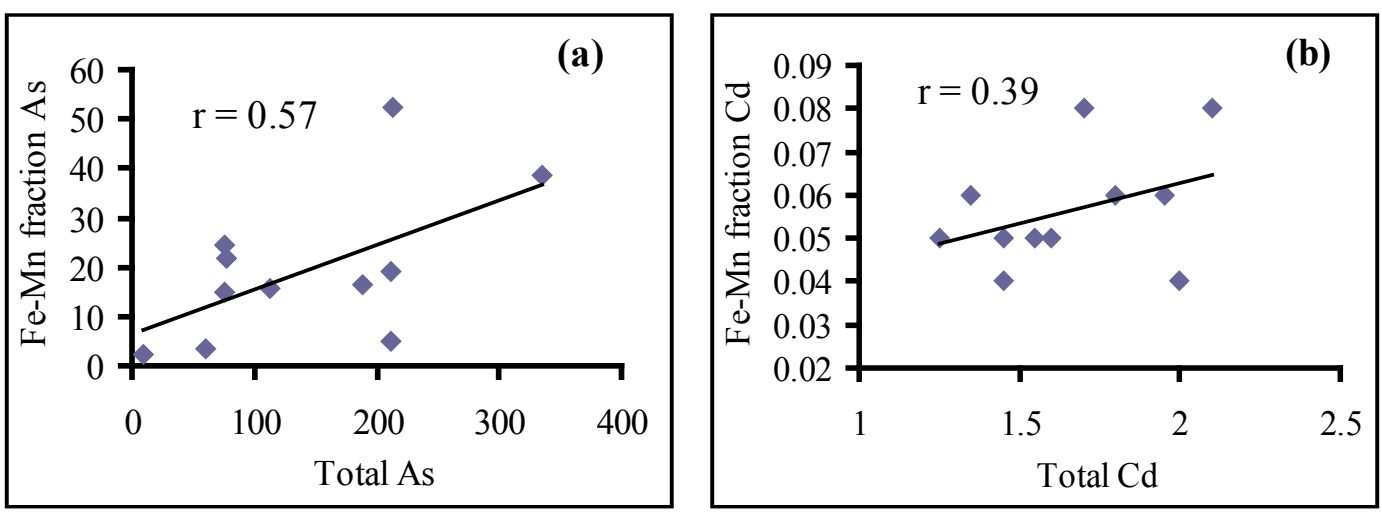

Fig. 5. Relationship between Fe-Mn fraction and (a) As and (b) Cd total content ( $\mu \mathrm{g} / \mathrm{g})$.

Egypt.J.Chem. 61, No.5 (2018) 


\section{Risk Assessment Code (RAC)}

The exchangeable and carbonate fractions contain the rapid bioavailable part of metals due to their weak bonds [50]. The Risk Assessment Code (RAC) was first used by Perin et al. [62] and is applied by many authors $[1,50,59]$, for the assessment of the environmental risk of soil pollution by heavy metals. RAC represents the percentage of the exchangeable and carbonate fractions which is calculated by the following equation:

$$
\mathrm{RAC}=100 \times(\mathrm{F} 1+\mathrm{F} 2) /(\mathrm{F} 1+\mathrm{F} 2+\mathrm{F} 3+\mathrm{F} 4+\mathrm{F} 5)
$$

The five classes of RAC are listed in Table (5). The calculated RAC of the studied sample ranges were $7.5-29.3 \%, 24.9-36.1 \%, 33.6-66.1 \%$ and $52.5-60 \%$ for $\mathrm{Pb}, \mathrm{Cr}$, As and $\mathrm{Cd}$, respectively (Fig. 6). These results indicate that there is a low to medium risk for $\mathrm{Pb}$, medium to high risk for $\mathrm{Cr}$, high to very high risk for As and very high risk for Cd (Table 5; Fig. 6). The order of pollution degrees of heavy metals is $(\mathrm{Pb}<\mathrm{Cr}<\mathrm{As}<\mathrm{Cd})$.

TABLE 5. RAC classes and the studied samples status for the studied metals.

\begin{tabular}{cccccc}
\hline \multicolumn{2}{c}{ RAC classification } & \multicolumn{4}{c}{ Studied samples status for the studied metals } \\
RAC value & Class & As & Cd & Cr & $\mathbf{P b}$ \\
$<\mathbf{1 \%}$ & No risk & - & - & - & - \\
$\mathbf{1}-\mathbf{1 0} \%$ & Low risk & - & - & - & $1,4,5,6,7,11$ \\
$\mathbf{1 1 - 3 0 \%}$ & Medium risk & - & - & $1,2,3,5,7,8,9$ & $2,3,8,9,10$ \\
$\mathbf{3 1 - 5 0 \%}$ & High risk & $1,2,4,5,6,8$, & - & $4,6,10,11$ & - \\
$>\mathbf{5 0} \%$ & Very high risk & $9,7,11$ & All samples & - & - \\
\hline
\end{tabular}

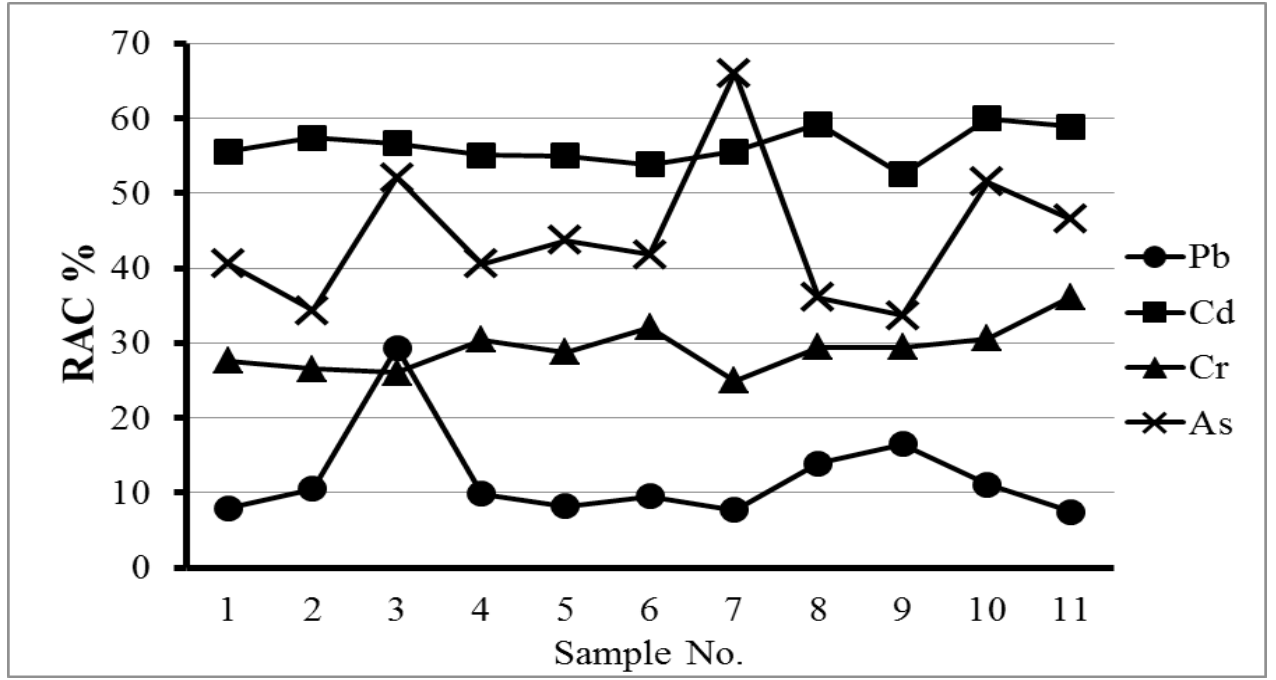

Fig. 6. RAC\% of the studied metals for the studied samples.

\section{Conclusion}

In the present study, the total concentration of $\mathrm{As}, \mathrm{Cd}, \mathrm{Pb}$ and $\mathrm{Cr}$ in the studied soil samples were higher than the average content of these metals in the world soil. The $\mathrm{I}_{\text {geo }}$ pointed out the pollution of soil with heavy metals especially arsenic. The pollution of soil with these metals may be attributed to the Sugar and chemical industries, bricks factories, traffic emissions, agricultural chemicals and urban runoff in the study area. Sequential extraction results indicate the incorporation of most $\mathrm{Pb}$ in the residual fraction while $\mathrm{As}, \mathrm{Cd}$ and $\mathrm{Cr}$ are mostly associated with the carbonate and residual fractions. The association of about $77.4 \%$ of As and $63.3 \%$ of $\mathrm{Cd}$ with the non-residual fractions $(\mathrm{F} 1-\mathrm{F} 4)$ support the anthropogenic source of these metals in the studied soil samples. On the other hand, the incorporation of $\mathrm{Pb}$ and $\mathrm{Cr}$ in the residual fraction indicates the geogenic origin of them in addition to anthropogenic inputs. The alkalinity of soil and its $\mathrm{CaCO}_{3}$ content play an important role in 
the distribution of the studied metals between the different fractions. The Risk Assessment Code (RAC) showed that the studied heavy metals are varied from low to very high risk. Finally, more detailed studies are recommended to investigate the organic and inorganic pollutants as well as monitor the sources of pollution.

\section{Acknowledgment}

We would like to thank the National Research Centre, Egypt, to use its laboratories and make the analyses. Also, we are grateful to Assiut University for assistance with more facilities.

\section{References}

1. Sarkar, S.K., Favas, P.J.C., Rakshit, D. and Satpathy, K.K., Geochemical speciation and risk assessment of heavy metals in soils and sediments, In Hernandez-Soriano M.C. (Ed.): Environmental risk assessment of soil contamination. InTech Publisher, DOI: 10.5772/57295 (2014).

2. Petit, M.D. and Rucandio, M.I., Sequential extractions for determination of cadmium distribution in coal fly ash, soil and sediment samples Anal. Chim. Acta, 401, 283291(1999).

3. Mohammed, S.S., Mohammed, M.B. and Musa, N., Use of sequential extraction to assess copper fractionation in soil and guinea corn from Kaduna Metropolis, Nigeria, Research J. Environ. Earth Sci., 4 (7), 704710 (2012).

4. Kabata-Pendias, A. and Pendias, H., Trace Elements in Soils and Plants, CRC Press, Boca Raton, FL (2001).

5. Shivakumar, D., Srikantaswamy, S., Sreenivasa, S. and Kiran, B.M.. Speciation and geochemical behaviour of heavy metals in industrial area soil of Mysore City, India. J. Environ. Prot., 3, 1384-1392(2012).

6. Tessier, A., Campbell, P.G.C. and Bisson, M., Sequential extraction procedure for the speciation of particulate trace metals, Anal. Chem., 51, 844-851(1979).

7. Elliot, H.A., Dempsey, B.A. and Maille, P.J., Content and fractionation of heavy metals in water treatment sludges., J. Environ. Qual., 19, 330-334(1990).

8. Lopez-Sanchez, J.F., Rubio, R. and Rauret, Egypt.J.Chem. 61, No.5 (2018)
G., Comparison of two sequential extraction procedure for trace metal partitioning in sediments, Int. J. Environ. Anal. Chem., 51, 113-121(1993).

9. Lo, I.M.C. and Yang, X.Y., Removal and redistribution of metals from contaminated soils by a sequential extraction method. Waste Manage., 18, 1-7(1998).

10. Gomez-Ariza, J.L., Giraldez, I., SanchezRodas, D. and Morales, E., Selectivity assessment of a sequential extraction procedure for metal mobility characterization using model phases, Talanta, 52(3), 545554(2000).

11. Phuong, N.K., Geochemical study of arsenic behavior in aquifer of the Mekong Delta, Vietnam, Ph.D. Thesis, Graduate School of Engineering, Kyushu Univ. (2008).

12. Alvarez, E., Fernandez-Sanjurjo, M.J., Nunez, A., Seco, N. and Corti, G., Aluminium fractionation and speciation in bulk and rhizosphere of a grass soil amended with mussel shells or lime, Geoderma, 173-174), 322-329 (2012).

13. Zaki, R., Ismail, E.A., Mohamed, W.S. and Ali, A.K., Impact of surface water and groundwater pollutions on irrigated soil, El Minia Province, northern Upper Egypt, $J$. Water Res. Prot., 7, 1467-1472 (2015).

14. Ali S.M., Sabae, S.Z., Fayez, M., Monib, M. and Hegazi, N.A., The influence of agroindustrial effluents on River Nile pollution, $J$. Adv. Res., 2, 85-95(2011)

15. Abu El Ella, E.M., Elnazer, A.A. and Salman S.A., The effect of human activities on the pollution of water in Southwest Giza area, Egypt, Water Sci. Technol.: Water Supply, 17 (5), 1368 - 1376 (2017).

16. USDA (Soil Survey Laboratory Methods Manual), Soil Survey Investigations, Washington, DC. Report, 42(3), (1996).

17. Muller G, Schwermetalle in den sedimenten des Rheins, Veranderungem Seit 1971. Schwermetalle in den sedimenten des Rheins, Veranderungem Seit 1971, Umschau, 79, 778-783(1979).

18. Zheng, X., Zhao, W., Yan, X., Shu, T., Xiong, Q. and Chen, F., Pollution characteristics and health risk assessment of airborne heavy 
metals collected from Beijing bus stations, Int. J. Environ. Res. Public Health, 12, 96589671(2015).

19. Milicevic, T., Relic, D., Skrivanj, S., Tesic, Z. and Popovic, A., Assessment of major and trace element bioavailability in vineyard soil applying different single extraction procedures and pseudo-total digestion. Chemosphere, 171, 284-293 (2017).

20. Koljonen, T., The geochemical atlas of Finland, Geol Survey of Finland, Espoo. $J$. Environ. Qual., 32, 2230-2237 (1992).

21. Gleyzes, C., Tellier, S. and Astruc, M., Fractionation studies of trace elements in contaminated soils and sediments: a review of sequential extraction procedures. Trends Anal. Chem., 21(6-7), 41-467(2002).

22. Rashad M., Assaad, F.F. and Shalaby, E.A., Effect of dissolved organic matter derived from waste amendments on the mobility of inorganic arsenic (III) in the Egyptian alluvial soil, Int. J. Energ. Environ., 4 (4), 677-686(2013).

23. Bertrand, I., Jaillard, B., Arvieu, J.C., Gregory, P.J. and Hinsinger, P., Dynamics of phosphorus in the rhizosphere of maize and rape grown on synthetic, phosphated calcite and goethite. New approaches to study chemical and physical changes in the rhizosphere, Plant Soil, 211 (1), 111-119 (1999).

24. Al-Busaidi, A.S. and Cookson, P., Salinity$\mathrm{pH}$ relationships in calcareous soils, Agri. Mar. Sci., 8, 41- 46(2003).

25. Hassan I.S.S., Geochemical Speciation and Enrichment of Toxic Heavy Metals in Nile Sediments and Soils in El-Tebbin Area, Egypt. Ph.D. Thesis, Fac Sci, Ain Shams Univ, Egypt, 161 p, (2015) .

26. Wahba, M.M., The relation between heavy metals distribution and particle size fractions in some Egyptian soils, Ital. J. Agron/Riv Agron., 2, 309-313 (2006).

27. Tamhan, R.J., Motiramani, D.P., Bali, T.P. and Donahue, R., Soil, their chemistry and fertility in tropical Asia. Prentice Hall of India, New Delhi. (1964).

28. Ortega, R.A., Peterson, G.A. and Westfall, D.G., Residue accumulation and changes in soil organic matter as affected by cropping intensity in no-till dryland agroecosystems Agron. J., 94, 944-954 (2002).

29. Markovic, J., Jovic, M., Smiciklas, I., Pezo, L., Sljivic-Ivanovic, M., Onjia, A. and Popovic, A., Chemical speciation of metals in unpolluted soils of different types: Correlation with soil characteristics and an ANN modelling approach, J Geochem Explor, doi: 10.1016/j.gexplo.2016.03.004, (2016).

30. Gui, D., Lei, J., Zenga, F., Guijin Mua, G., Zhu, J., Wang, H. and Zhang, Q., Characterizing variations in soil particle size distribution in oasis farmlands: A case study of the Cele Oasis, Math. Comput. Model., 51, 1306-1311(2010).

31. Folk, L., Petrology of sedimentary rocks, Hemplill, Austin, Texas, 182p, (1974).

32. Sarlak, M.R., Characterization of the Particle Size Fraction Associated Heavy Metals in Arable soils from Ahwaz size, Iran, Int. J. Curr. Microbiol. App. Sci, 4 (7), 65-75(2015).

33. Smith, E., Naidu, R. and Alston A.M., Arsenic in the soil environment: a review, Adv. Agron., 64, 149-195(1998).

34. Xie, X., Wang, Y., Li, J., Wu, Y. and Duan, M., Soil geochemistry and groundwater contamination in an arsenic-affected area of the Datong Basin, China, Environ. Earth Sci., 71, 3455-3464 (2014).

35. Badawy, W., Chepurchenko, O.Y., El Samman, H. and Frontasyeva, M.V., Assessment of industrial contamination of agricultural soil adjacent to Sadat City, Egypt, Ecol Chem Eng S., 23(2), 297-310(2016).

36. Rahim, I.S., Ageeb, G.W. and Kotb, M.M., Arsenic in soil and its relationship with paddy soil environment in Egypt, Egypt. J. Soil Sci., 49 (3), 311-318 (2009).

37. Shaheen, S.M., Kwon, E.E., Biswas, J.K., Tack, F.M.G., Ok, Y.S. and Rinklebe, J., Arsenic, chromium, molybdenum, and selenium: Geochemical fractions and potential mobilization in riverine soil profiles originating from Germany and Egypt, Chemosphere, 180, 553-563 (2017).

38. Safar, Z., Labib, M.W., Lotfi, W. and Khalil, M.N., Characterization of Contamination Egypt.J.Chem. 61, No.5 (2018) 
Around the Largest Lead Smelter in Egypt Carried Out Through a Cooperation Program between USA and Egypt, Field Actions Science Reports, 7, URL: http://factsreports. Revues.org/3831 (2014).

39. Kalbitz K. and Wennrich R., Mobilization of heavy metals and arsenic in polluted wetland soils and its dependence on dissolved organic matter, Sci. Total Environ., 209, 27-39(1998).

40. Zhang, C., Wu, P., Tang, C., Han, Z. and Sun, J., Assessment of arsenic distribution in paddy soil and rice plants of a typical Karst Basin affected by acid mine drainage in Southwest China, Environ. Pollut., 2 (2), 27-38 (2013).

41. Liao, X., Chen, T., Xie, H. and Liu, Y., Soil As contamination and its risk assessment in areas near the industrial districts of Chenzhou City, Southern China, Environ. Int., 31, 791 798 (2005).

42. Al Naggar, Y., Naiem, E., Mohamed, M., Giesy, J.P. and Seif, A., Metals in agricultural soils and plants in Egypt. Toxicol. Environ Chem., 96(5), 730-742 (2014).

43. Abd Elgawad, M., Mohamed, H.A.A., Shendi, M.M. and Ghabour, S.I., Status of some heavy metals in Fayoum District soils, The $3^{\text {rd }}$ Conf. sustainable agric. Develop., Fac. A gric., Fayoum Univ., 12-14 Nov., 507526 (2007).

44. Salman, S.A.; Elnazer, A.A. and El Nazer, H.A., Integrated mass balance of some heavy metals fluxes in Yaakob village, south Sohag, Egypt, Int. J. Environ. Sci. Technol., 14, 1011-1018 (2017).

45. Elnazer, A.A., Salman, S.A., Seleem, E.M. and Abu El Ella, E.M., Assessment of Some Heavy Metals Pollution and Bioavailability in Roadside Soil of Alexandria-Marsa Matruh Highway, Egypt, Intern. J. of Ecol., Article ID 689420, doi:10.1155/2015/689420, 7p, (2015).

46. Omer, A.A.M., Geological, mineralogical and geochemical studies on the Neogene and Quaternary Nile basin deposits, Qena- Assiut stretch, Egypt, Ph.D. Thesis, Geol. Dept., Fac. Sci., South Valley Univ., Egypt, (1996).

47. Omran, E.E. and Abd El Razek A.A., Mapping and screening risk assessment of

Egypt.J.Chem. 61, No.5 (2018) heavy metals concentrations in soils of the Bahr El-Baker Region, Egypt, J. Soil Sci. Environ. Manage., 6 (7), 182-195 (2012).

48. Salman S.A., Geochemical and environmental studies on the territories West River Nile, Sohag Governorate-Egypt, Ph.D. thesis, Fac Sci, Al-Azhar Univ, Egypt, 314 p., (2013).

49. Gabarron, M., Faz, A., Martinez-Martinez, S., Zornoza, R. and Acosta, J.A., Assessment of metals behaviour in industrial soil using sequential extraction, multivariable analysis and a geostatistical approach., $J$ Geochem Explor., 172, 174-183(2017).

50. Sundaray, S.K., Nayak, B.B., Lin, S. and Bhatta, D., Geochemical speciation and risk assessment of heavy metals in the river estuarine sediments-case study: Mahanadi basin, India, J. Hazard. Mater., 186, $1837-$ 1846 (2011).

51. Okorie, I.A., Determination of potentially toxic elements (PTEs) and an assessment of environmental health risk from environmental matrices, Ph.D. Thesis, School of Applied Sciences, Northumbria Univ. (2010).

52. Chakraborty, P., Babu, P.V.R. and Sarma, V.V., A study of lead and cadmium speciation in some estuarine and coastal sediments, Chem. Geol., 294-295, 217-225 (2012).

53. Stone, M. and Droppo, I.G., Distribution of lead, copper and zinc in size-fractionated river bed sediment in two agricultural catchments of southern Ontario, Canada Environ. Poll., 93, 353-362 (1996).

54. Ma, J., Risk assessment and sequestered contamination evaluation for legacy heavy metal contaminants in Cleveland area Brownfield, Dept. Civil Engin., Case Western Reserve Univ., (2005).

55. Wuana R.A., Adie, P.A. and Asegh, I.N., Seasonal variation in bioavailability of some toxic metals in waste dump soils of Makurdi, North-Central Nigeria., J. Biodiv. Environ. Sci., 2(11), 7-17 (2012).

56. Kashem, M.A., Singh, B.R. and Kawai, S., Mobility and distribution of cadmium, nickel and zinc in contaminated soil profiles from Bangladesh, Nutr. Cycl. Agroecosyst., 77, 187-198 (2007).

57. Okoro, H.K., Fatoki, O.S., Adekola, F.A., 
Ximba, B.J. and Snyman, R.G., A review of sequential extraction procedures for heavy metals speciation in soil and sediments., Open Access Scientific Reports, 1 (3), 181(2012), doi:10.4172/scientificreports. 181

58. Filgueiras, A.V., Lavilla, I. and Bendicho, C., Chemical Sequential Extraction for Metal Partitioning in Environmental Solid Samples, J. Environ. Monitor., 4, 823-857 (2002).

59. Matong, J.M., Nyaba, L. and Nomngongo, P.N., Fractionation of trace elements in agricultural soils using ultrasound assisted sequential extraction prior to inductively coupled plasma mass spectrometric determination, Chemosphere, 154, 249-257 (2016).
60. Abu Khatita, A.M., Assessment of soil and sediment contamination in the Middle Nile Delta area (Egypt) - Geo-Environmental study using combined sedimentological, geophysical and geochemical methods, Ph.D. Thesis, Fac. Nat. Sci. Friedrich-Alexander Univ. (FAU), Germany, 224p, (2011).

61. Goher, M.E., Farhat, H.I., Abdo, M.H. and Salem, S.G., Metal pollution assessment in the surface sediment of Lake Nasser, Egypt, Egypt. J. Aquat. Res., 40, 213-224 (2014).

62. Perin, G., Craboledda, L., Lucchese, M, Cirillo, R., Dotta, L., Zanette, M.L. and Orio, A., Heavy metal speciation in the sediments of Northern Adriatic Sea-a new approach for environmental toxicity determination, In: Lekkas, T.D. (Ed.), Heavy Metal in the Environment. CEP Consultants: Edinburg, pp 454-456 (1985).

(Received 11/3/2018;

accepted 11/7/2018)

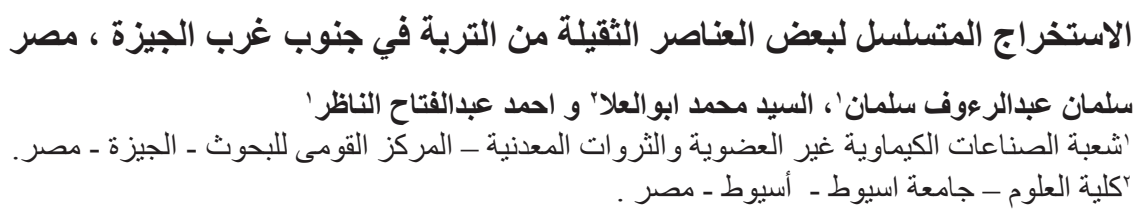

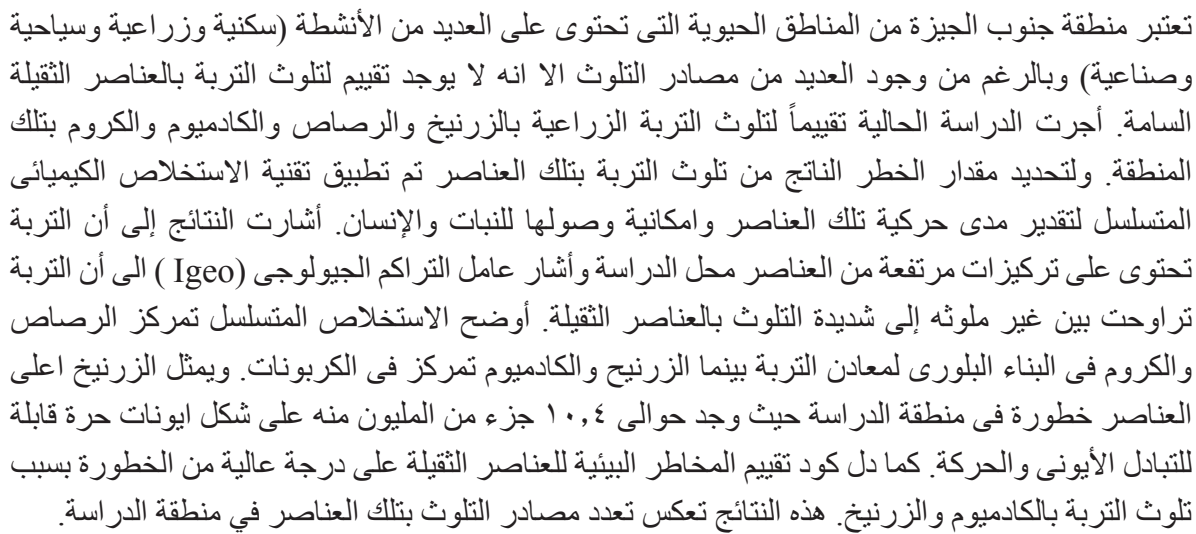

